Keywords: CDK4/6 inhibitor; abemaciclib; BRAF inhibitor; vemurafenib; pharmacokinetic/pharmacodynamic; modelling; dose optimisation; resistance

\title{
Optimising the combination dosing strategy of abemaciclib and vemurafenib in BRAF-mutated melanoma xenograft tumours
}

\author{
Sonya C Tate ${ }^{\star},{ }^{1}$, Teresa F Burke ${ }^{2}$, Daisy Hartman ${ }^{2}$, Palaniappan Kulanthaivel ${ }^{2}$, Richard P Beckmann ${ }^{2}$ and \\ Damien M Cronier ${ }^{1}$ \\ ${ }^{1}$ Global PK/PD, Eli Lilly and Company, Erl Wood Manor, Windlesham, Surrey GU20 6PH, UK and ${ }^{2}$ Eli Lilly and Company, \\ Lilly Corporate Center, Indianapolis, IN 46285, USA
}

\begin{abstract}
Background: Resistance to BRAF inhibition is a major cause of treatment failure for BRAF-mutated metastatic melanoma patients. Abemaciclib, a cyclin-dependent kinase 4 and 6 inhibitor, overcomes this resistance in xenograft tumours and offers a promising drug combination. The present work aims to characterise the quantitative pharmacology of the abemaciclib/vemurafenib combination using a semimechanistic pharmacokinetic/pharmacodynamic modelling approach and to identify an optimum dosing regimen for potential clinical evaluation.
\end{abstract}

Methods: A PK/biomarker model was developed to connect abemaciclib/vemurafenib concentrations to changes in MAPK and cell cycle pathway biomarkers in A375 BRAF-mutated melanoma xenografts. Resultant tumour growth inhibition was described by relating (i) MAPK pathway inhibition to apoptosis, (ii) mitotic cell density to tumour growth and, under resistant conditions, (iii) retinoblastoma protein inhibition to cell survival.

Results: The model successfully described vemurafenib/abemaciclib-mediated changes in MAPK pathway and cell cycle biomarkers. Initial tumour shrinkage by vemurafenib, acquisition of resistance and subsequent abemaciclib-mediated efficacy were successfully captured and externally validated. Model simulations illustrate the benefit of intermittent vemurafenib therapy over continuous treatment, and indicate that continuous abemaciclib in combination with intermittent vemurafenib offers the potential for considerable tumour regression.

Conclusions: The quantitative pharmacology of the abemaciclib/vemurafenib combination was successfully characterised and an optimised, clinically-relevant dosing strategy was identified.

The recent approval of the BRAF inhibitors, vemurafenib and dabrafenib, represents a major improvement in the prognosis of patients with BRAF-mutated (V600E/K) metastatic melanoma. In a pivotal phase III registration trial, vemurafenib demonstrated significantly improved progression-free survival (PFS) over dacarbazine (5.3 vs 1.6 months) (Chapman et al., 2011), with a similar improvement also observed for dabrafenib (Hauschild et al., 2012). However, the majority of patients who initially responded to either vemurafenib or dabrafenib developed resistance and ultimately relapsed after 6-12 months of treatment
(Chapman et al., 2011; Hauschild et al., 2012). Although combination with an MEK inhibitor further improved PFS (9.4 vs 5.8 months), it was unable to prevent acquisition of resistance to BRAF inhibition (Flaherty et al., 2012). As such, resistance to vemurafenib/dabrafenib remains an area of significant unmet medical need for patients with BRAF-mutated metastatic melanoma.

Tumour biopsies obtained from relapsed patients typically exhibit MAPK reactivation (Trunzer et al., 2013; Shi et al., 2014), as signified by elevation of ERK1/2 phosphorylation (pERK)

*Correspondence: Dr SC Tate; E-mail: tate_sonya@lilly.com 
(Trunzer et al., 2013) and Cyclin D1 (Smalley et al., 2008). This mode of resistance to BRAF inhibition has been successfully replicated in preclinical xenograft studies in mice with human BRAF-mutant melanoma cell lines (Das Thakur et al., 2013; Yadav et al., 2014). Using these resistant cell lines, it was shown that although vemurafenib still inhibits pERK, the MAPK pathway is upregulated such that maximum vemurafenib-mediated inhibition cannot sufficiently suppress pERK to induce apoptosis (Das Thakur et al., 2013). Furthermore, while a period of chronic vemurafenib therapy induces pERK elevation, temporary cessation of treatment allows pERK to return to near-normal levels and subsequent reintroduction of vemurafenib becomes efficacious once more (Das Thakur et al., 2013). In the clinic, patients receiving vemurafenib on an intermittent schedule have demonstrated response to treatment (Dooley et al., 2014; Koop et al., 2014), with some evidence of reduced toxicity (Dooley et al., 2014). Furthermore, those rechallenged with vemurafenib after previously progressing on treatment exhibited further response to BRAF inhibition (Seghers et al., 2012; Romano et al., 2013). However, all clinical evidence of the benefit of an intermittent schedule for BRAF inhibitors to date is restricted to isolated case studies.

While intermittent therapy may delay resistance to vemurafenib, using drug combinations to prevent or exploit MAPK pathway reactivation may further improve clinical efficacy over BRAF inhibition alone. The potential combination with a cyclindependent kinase 4 and 6 (CDK4/6) inhibitor, such as abemaciclib or palbociclib, is of particular interest (Sheppard and McArthur, 2013; Yadav et al., 2015). Abemaciclib recently demonstrated a level of efficacy in vemurafenib-resistant A375 xenograft tumours which was far greater than that expected in treatment-naïve tumours (Yadav et al., 2014). Using western blotting, Yadav et al. (2013) noted increased cleaved PARP levels in vemurafenibresistant cells treated with retinoblastoma protein $(\mathrm{Rb})$ siRINA, suggesting increased dependency on $\mathrm{Rb}$ expression for cell survival. Chronic dosing with a CDK4/6 inhibitor such as abemaciclib suppresses phosphorylation of Rb (pRb) (Gelbert et al., 2014; Tate et al., 2014), which in turn downregulates Total Rb (Yadav et al., 2013) as a result of the inherent autoregulation of the E2F1-Rb pathway (Shan et al., 1994). The authors therefore proposed that abemaciclib-mediated inhibition of Total $\mathrm{Rb}$ in vemurafenibresistant tumours may provide additional clinical benefit over the currently approved therapies for patients with BRAF-mutated metastatic melanoma (Yadav et al., 2013, 2014).

While intermittent vemurafenib and combined vemurafenib/ abemaciclib therapy have proved promising in preclinical studies (Das Thakur et al., 2013; Yadav et al., 2014), the optimal dosing schedule that could maximise its clinical efficacy remains to be identified. The objective of this study was therefore to explore dosing strategies for the combination of abemaciclib and vemurafenib by means of a semimechanistic PK/PD model, which captures the quantitative pharmacology of abemaciclib overcoming resistance to vemurafenib. To this end, an existing semimechanistic $\mathrm{PK} / \mathrm{PD}$ model for abemaciclib (Tate et al., 2014) was further developed to include vemurafenib-mediated inhibition of the MAPK pathway and tumour shrinkage, acquisition of resistance through MAPK pathway reactivation and subsequent abemaciclibmediated efficacy as a result of Total Rb inhibition. This model, once externally validated, was used to identify the combination treatment schedule yielding the best predicted response in A375 xenograft tumours. Model simulations not only supported existing preclinical studies reporting the benefit of intermittent vemurafenib therapy over continuous treatment (Das Thakur et al., 2013) but also indicated that daily administration of abemaciclib in combination with intermittent vemurafenib therapy offers the potential for considerable tumour regression. To our knowledge, this is the first PK/PD modelling approach to formalise acquisition of resistance to vemurafenib in BRAF-mutated melanoma and to mechanistically evaluate dose schedule optimisation for combination therapies in oncology.

\section{MATERIALS AND METHODS}

\section{In vivo experiments}

Biomarker modulation in colo-205 xenograft tumours. The in vivo studies evaluating abemaciclib-mediated cell cycle arrest in colo-205 xenograft tumours used in this work were described previously (Tate et al., 2014). In addition to phospho-(ser780)-Rb (pRb), topoisomerase II $\alpha$ (TopoII $\alpha$ ) and phospho-(ser10)-histone $\mathrm{H} 3$ ( $\mathrm{pHH} 3$ ), tumour lysates from selected studies were also used to evaluate inhibition of Total $\mathrm{Rb}$ after abemaciclib. In the first study, mice received a single oral $50 \mathrm{mg} \mathrm{kg}^{-1}$ dose and tumour tissue was collected at 1, 6, 24, 36 and $48 \mathrm{~h}$; in the second study, mice received $50 \mathrm{mg} \mathrm{kg}^{-1}$ orally once a day for 56 days, with tumour tissue collections at 28 and 56 days ( $n=5$ per time point). A summary of the available experimental data is provided in Supplementary Table 1.

Biomarker modulation in A375 xenograft tumours. A series of in vivo experiments were performed to evaluate the dose-response and time course of abemaciclib- or vemurafenib-mediated modulation of biomarkers in mice bearing A375 xenograft tumours. First, the time course of abemaciclib-mediated target engagement and cell cycle arrest was assessed after a single 45 or $90 \mathrm{mg} \mathrm{kg}^{-1}$ oral dose, with blood and tumour tissue collection occurring at 1, 6, 24, 36 and $48 \mathrm{~h}$ postdose. Second, the time course of vemurafenib-mediated biomarker modulation was evaluated at a single $15 \mathrm{mg} \mathrm{kg}^{-1}$ oral dose, where blood and tumour tissue were collected at $1,2,6,12,24$ and $48 \mathrm{~h}$ postdose. Third, the dose response of vemurafenib was assessed after a single oral dose of $7.5,30$ or $60 \mathrm{mg} \mathrm{kg}^{-1}$, with blood and tumour tissue collection at 4,8 and $24 \mathrm{~h}$ postdose ( $n=5$ per time point). All tumour tissue was evaluated for the cell cycle biomarkers, pRb, TopoII $\alpha, \mathrm{pHH} 3$ and Total $\mathrm{Rb}$. In addition, tumour tissue obtained in the vemurafenib studies was also assayed for phospho-(ser217/221)mitogen-activated protein kinase kinase (pMEK), phospho(thr202/tyr204)-ERK (pERK) and Cyclin D1.

Tumour growth inhibition in A375 xenograft tumours. First, the in vivo efficacy of the abemaciclib and vemurafenib combination was evaluated. For 21 days, mice bearing A375 xenograft tumours received either the combination or monotherapy of vemurafenib two times a day at $10 \mathrm{mg} \mathrm{kg}^{-1}$ and abemaciclib daily at $45 \mathrm{mg} \mathrm{kg}^{-1}$ ( $n=8$ per dose level). Treated tumour growth was compared with tumour growth in mice receiving one of three vehicle formulations $(n=24)$. Tumour size was measured every 3-4 days for $\sim 6$ weeks after the first dose.

Second, the in vivo efficacy of abemaciclib in mice bearing vemurafenib-resistant A375 xenograft tumours was evaluated. For 48 days, mice received vemurafenib at $15 \mathrm{mg} \mathrm{kg}^{-1}$ two times a day to allow resistance to develop; mice then received either $90 \mathrm{mg} \mathrm{kg}^{-1}$ abemaciclib daily or continued on vemurafenib therapy for 28 days ( $n=8$ per group). An additional eight mice received a vehicle formulation as a control. Tumour size was measured every 3-4 days for $\sim 13$ weeks after the first dose.

All animal studies were performed in accordance with American Association for Laboratory Animal Care institutional guidelines, and all protocols were approved by the Eli Lilly and Company Institutional Animal Care and Use Committee.

Development of the integrated semimechanistic PK/PD model. While the melanoma cell line, A375, was the focus of the present work, there is wealth of data available for the preclinical tool cell line, colo-205 (Gelbert et al., 2014; Tate et al., 2014; 
Yadav et al., 2014). As the existing PK/PD model was shown to accurately predict biomarker response to abemaciclib in either cell line (Tate et al., 2014), this allowed the authors to capitalise on the available data and develop the cell cycle model using Total $\mathrm{Rb}$ response data obtained in colo-205. As such, the following describes initial model development using colo-205 biomarker data, before validated translation to A375 to incorporate biomarker response to vemurafenib and efficacy.

PK/biomarker model for abemaciclib. A semimechanistic PK/PD model was previously developed to describe abemaciclib target engagement and resulting cell cycle arrest in mice bearing colo-205 xenograft tumours (Tate et al., 2014). Briefly, the model comprises four transit compartments, each corresponding to early G1, late G1, S and G2/M cell cycle phases in a sequential, open-loop manner. The biomarkers, $\mathrm{pRb}$, TopoII $\alpha$ and $\mathrm{pHH} 3$, represent the change in cell phase density in late G1, S and G2/M phases, respectively (Gurley et al., 1974; DeCaprio et al., 1989; Goswami et al., 1996; Kitagawa et al., 1996), where abemaciclib inhibits production of $\mathrm{pRb}$ and thus induces cell cycle arrest in the G1 phase (Gelbert et al., 2011). This model was further developed to include inhibition of Total Rb caused by abemaciclib-mediated $\mathrm{pRb}$ inhibition, as a result of autoregulation of the E2F1-Rb pathway (Shan et al., 1994) (see Equations 9-13). The model was refitted with all colo-205 biomarker data previously used for model development, with the addition of Total $\mathrm{Rb}$ data obtained after single or multiple doses of $50 \mathrm{mg} \mathrm{kg}^{-1}$ abemaciclib. The rate constants for the cell cycle model were then recalculated using cell phase density (Huang et al., 2007; Lam et al., 2011), as shown previously (Tate et al., 2014), to predict abemaciclib-mediated inhibition of $\mathrm{pRb}$, TopoII $\alpha, \mathrm{pHH} 3$ and Total Rb in A375 xenograft tumours.

PK model for vemurafenib. The plasma-concentration time course of vemurafenib in mice bearing xenograft tumours was described by a one-compartment model with saturable absorption and linear clearance. The PK model is given by the following differential equations:

$$
\begin{aligned}
& \frac{\mathrm{d} A_{\mathrm{Gut}}}{\mathrm{d} t}=-\frac{V_{\mathrm{max}} \cdot A_{\mathrm{Gut}}}{K_{\mathrm{m}}+A_{\mathrm{Gut}}} \\
& V \cdot \frac{\mathrm{d} C_{\text {Vemurafenib }}}{\mathrm{d} t}=\frac{V_{\mathrm{max}} \cdot A_{\mathrm{Gut}}}{K_{\mathrm{m}}+A_{\mathrm{Gut}}}-C \mathrm{~L} \cdot C_{\text {Vemurafenib }}
\end{aligned}
$$

where $A_{\text {Gut }}$ is the amount of drug in the gut, $C_{\text {Vemurafenib }}$ is the concentration of vemurafenib in the plasma, $V_{\max }$ and $K_{\mathrm{m}}$ describe the saturable absorption, CL denotes drug clearance from plasma and $V$ is the volume of distribution. Initial conditions for each PK model compartment were set to zero, except $A_{\text {Gut }}$, which was set equal to the dose.

Biomarker model for abemaciclib and vemurafenib. The biomarker model for vemurafenib was developed using A375 xenograft tumour data to describe drug-induced changes in the MAPK pathway. An indirect response model was used to relate vemurafenib plasma concentrations to inhibition of pMEK (Yang et al., 2012), which was in turn directly related to inhibition of pERK (Dhillon et al., 2007; Yang et al., 2012), where IC $_{50, \text { Vemurafenib }}$ is the potency of vemurafenib and $k_{\text {out,pMEK }}$ is the turnover rate constant:

$$
\begin{aligned}
\frac{\mathrm{dpMEK}}{\mathrm{d} t}= & k_{\text {in,pMEK }} \cdot\left(1-\frac{C_{\text {Vemurafenib }}}{\mathrm{IC}_{50, \text { Vemurafenib }}+C_{\text {Vemurafenib }}}\right) \\
& -k_{\text {out }, \text { pMEK }} \cdot \mathrm{pMEK} \\
\frac{\mathrm{dpERK}}{\mathrm{d} t}= & \frac{\mathrm{dpMEK}}{\mathrm{d} t}
\end{aligned}
$$

A series of transit compartments then describe the impact of pERK inhibition on Cyclin D1 (Terada et al., 1999; Stacey, 2003) and the downstream effect of Cyclin D1 inhibition on the cell cycle (Stacey, 2003), where $k_{\text {out,Cyclin D1 }}$ is the Cyclin D1 turnover rate constant:

$$
\begin{aligned}
\frac{\mathrm{dCyclin} \mathrm{D} 1}{\mathrm{~d} t}= & k_{\mathrm{in}, \text { Cyclin D1 }} \cdot \frac{\mathrm{pERK}}{\mathrm{pERK}_{0}} \\
& -k_{\text {out,Cyclin D1 }} \cdot \text { Cyclin D1 }
\end{aligned}
$$

Three transit compartments were included to account for the apparent delay between vemurafenib-mediated inhibition of Cyclin $\mathrm{D} 1$ and $\mathrm{pRb}$ inhibition:

$$
\begin{aligned}
\frac{\mathrm{dCyclin} \mathrm{D} 1_{\text {Trans1 }}}{\mathrm{d} t}= & k_{\text {out,Cyclin D1 }} \cdot \text { Cyclin D1 } \\
& -k_{\text {out,Cyclin D1 }} \cdot \text { Cyclin D1 } 1_{\text {Trans1 }} \\
\frac{\mathrm{dCyclin} \mathrm{D} 1_{\text {Trans2 }}}{\mathrm{d} t}= & k_{\text {out,Cyclin D1 }} \cdot \text { Cyclin D1 } 1_{\text {Trans1 }} \\
& -k_{\text {out,Cyclin D1 }} \cdot \text { Cyclin D } 1_{\text {Trans2 }} \\
\frac{\mathrm{dCyclin} \mathrm{D1} 1_{\text {Trans3 }}}{\mathrm{d} t}= & k_{\text {out,Cyclin D1 }} \cdot \text { Cyclin D1 } 1_{\text {Trans2 }} \\
& -k_{\text {out,Cyclin D1 }} \cdot \text { Cyclin D1 } 1_{\text {Trans3 }}
\end{aligned}
$$

Inhibition of pRb both directly by abemaciclib (Gelbert et al., 2011) and indirectly by vemurafenib (Stacey, 2003; Tap et al., 2010) was incorporated into the cell cycle model, where $I_{\max }$ is the maximum drug effect and $\mathrm{IC}_{50, \text { Abemaciclib }}$ is the drug potency:

$$
\begin{aligned}
& \frac{\mathrm{d} P}{\mathrm{~d} t}=k_{\mathrm{in}}-k_{\mathrm{el}} \cdot P \\
& \frac{\mathrm{dpRb}}{\mathrm{d} t}=k_{\mathrm{R}} \cdot P \cdot\left(1-\frac{I_{\max } \cdot C_{\text {Abemaciclib }}}{\mathrm{IC}_{50, \text { Abemaciclib }}+C_{\text {Abemaciclib }}}\right) \\
& \cdot \frac{\text { Cyclin } \mathrm{D} 1_{\text {Trans } 3}^{\gamma_{\text {Cyclin1 }}}}{\text { Cyclin } \mathrm{D} 1_{0}^{\gamma_{\text {CyclinD1 }}}}-k_{\mathrm{G} 1 \mathrm{~S}} \cdot \mathrm{pRb} \\
& \frac{\mathrm{dTopoII} \alpha}{\mathrm{d} t}=k_{\mathrm{G} 1 \mathrm{~S}} \cdot \mathrm{pRb}-k_{\mathrm{SG} 2} \cdot \operatorname{TopoII} \alpha \\
& \frac{\mathrm{dpHH} 3}{\mathrm{~d} t}=k_{\mathrm{SG} 2} \cdot \text { TopoII } \alpha-k_{\mathrm{MG} 1} \cdot \mathrm{pHH} 3
\end{aligned}
$$$$
-k_{\mathrm{R}} \cdot P \cdot\left(1-\frac{I_{\max } \cdot C_{\mathrm{Abemaciclib}}}{\mathrm{IC}_{50, \mathrm{Abemaciclib}}+C_{\mathrm{Abemaciclib}}}\right) \cdot \frac{\mathrm{Cyclin} \mathrm{D} 1_{\mathrm{Trans} 3}^{\gamma_{\text {Cyclin } 1}}}{\operatorname{Cyclin} \mathrm{D} 1_{0}^{\gamma_{\mathrm{Cyclin} D 1}}}
$$

The inhibitory effect of $\mathrm{pRb}$ downregulation on the expression of Total $\mathrm{Rb}$, caused by autoregulation of the $\mathrm{Rb}$ pathway through E2F-1 (Shan et al., 1994), was included in the biomarker model, where $k_{\text {out,Total } \mathrm{Rb}}$ is the Total $\mathrm{Rb}$ turnover rate constant:

$$
\frac{\mathrm{dTotal} \mathrm{Rb}}{\mathrm{d} t}=k_{\text {in,Total Rb }} \cdot \frac{\mathrm{pRb}^{\gamma_{\mathrm{pRb}}}}{\mathrm{pRb}_{0}^{\gamma_{\mathrm{pRb}}}}-k_{\text {out,Total Rb }} \cdot \text { Total Rb }
$$

Each zero-order input in the above equations is defined as the product of the turnover rate (plus elimination rate, where relevant) and the baseline level of each biomarker:

$$
\begin{aligned}
& k_{\text {in }, \mathrm{pMEK}}=k_{\text {out,pMEK }} \cdot \mathrm{pMEK}_{0} \\
& k_{\text {in,Cyclin D1 }}=k_{\text {out,Cyclin D1 }} \cdot \text { Cyclin } 1_{0} \\
& k_{\text {in }}=\left(k_{\mathrm{el}}+k_{\mathrm{R}}\right) \cdot P_{0} \\
& k_{\text {in,Total Rb }}=k_{\text {out }, \text { Total Rb }} \cdot \text { Total Rb }_{0}
\end{aligned}
$$

As described previously (Tate et al., 2014), the rate constants, $k_{\mathrm{R}}$, 
$k_{\mathrm{G} 1 \mathrm{~S}}, k_{\mathrm{SG} 2}$ and $k_{\mathrm{MG} 1}$, drive the rate of transition of the cells through each of the cell cycle phases. The initial phase distributions of the colo-205 and A375 cell lines (Huang et al., 2007; Lam et al., 2011) were used to adjust baseline levels of $\mathrm{pRb}$, TopoII $\alpha$ and $\mathrm{pHH} 3$ and to calculate the rate constants:

$$
\begin{aligned}
& k_{\mathrm{G} 1 \mathrm{~S}}=k_{\mathrm{R}} \cdot \frac{P_{0}}{\mathrm{pRb_{0 }}} \\
& k_{\mathrm{SG} 2}=k_{\mathrm{G} 1 \mathrm{~S}} \cdot \frac{\mathrm{pRb}_{0}}{\mathrm{TopoII}_{0}} \\
& k_{\mathrm{MG} 1}=k_{\mathrm{SG} 2} \cdot \frac{\mathrm{TopoII}_{0}}{\mathrm{pHH} 3}
\end{aligned}
$$

The initial conditions for all other biomarkers, pMEK, pERK, Cyclin $\mathrm{D} 1$, Total $\mathrm{Rb}$ and all associated transit compartments, were set equal to the baseline level of 100, representing the percentage of control.

Effect of emerging resistance on the biomarker model. The emerging resistance of the tumour to vemurafenib by the upregulation of the MAPK pathway (Das Thakur et al., 2013) was incorporated into the biomarker model by use of a modulator compartment. In the model, the chronic presence of vemurafenib drives upregulation of the modulator compartment, which in turn increases production of pMEK, pERK and Cyclin D1. Although inhibition of the MAPK pathway by vemurafenib still occurs, the peak inhibition level no longer falls below non-resistant baseline levels of each biomarker, in accordance with previous experimental observations (Das Thakur et al., 2013). As a result, vemurafenib-mediated tumour shrinkage no longer occurs, and tumour growth resumes.

The modulator compartment (Mod) and its effect on pMEK is described as follows, where Scalar is the magnitude of vemurafenib effect on the modulator compartment and $k_{\text {out,Mod }}$ is the turnover rate:

$$
\begin{aligned}
& \frac{\mathrm{dMod}}{\mathrm{d} t}=k_{\text {in,Mod }} \cdot\left(1+\text { Scalar } \cdot C_{\text {Vemurafenib }}\right)-k_{\text {out,Mod }} \cdot \operatorname{Mod} \\
& \frac{\mathrm{dpMEK}}{\mathrm{d} t}=k_{\mathrm{in}, \mathrm{pMEK}} \cdot\left(1-\frac{C_{\text {Vemurafenib }}}{\mathrm{IC}_{50, \text { Vemurafenib }}+C_{\text {Vemurafenib }}}\right) \\
& \frac{\operatorname{Mod}}{\operatorname{Mod}_{0}}-k_{\text {out }, \mathrm{pMEK}} \cdot \mathrm{pMEK}
\end{aligned}
$$

The zero-order input for the modulator compartment is defined below:

$$
k_{\text {in, Mod }}=k_{\text {out }, \operatorname{Mod}} \cdot \operatorname{Mod}_{0}
$$

Tumour model. The growth rate of A375 xenograft tumours in control mice was described using the model previously developed by Simeoni et al (2004). Tumour growth was affected in one of three ways: (1) by inhibition of the cell cycle $\left(E_{\mathrm{pHH}}\right)$ (Tate et al., 2014), (2) by apoptosis triggered by the downstream effect of pERK inhibition ( $\left.E_{\mathrm{pERK}}\right)$ (Mandal et al., 2014) and (3) by increasing dependence on Total $\mathrm{Rb}$ for survival under vemurafenib-resistant conditions ( $E_{\text {Total } \mathrm{Rb}}$ ) (Yadav et al., 2013)

$$
\begin{aligned}
\frac{\mathrm{d} T_{\mathrm{g}}}{\mathrm{d} t}= & E_{\mathrm{pHH} 3} \cdot \frac{\lambda_{0} \cdot T_{\mathrm{g}}}{\left[1+\left(\frac{\lambda_{0}}{\lambda_{1}} \cdot T_{\mathrm{g}}\right)^{\psi}\right]^{\frac{1}{\psi}}}-E_{\mathrm{pERK}} \cdot k_{\text {death,pERK }} \cdot T_{\mathrm{g}} \\
& -E_{\text {TotalRb }} \cdot k_{\text {death,TotalRb }} \cdot T_{\mathrm{g}}
\end{aligned}
$$

The exponential and linear growth parameters are denoted by $\lambda_{0}$ and $\lambda_{1}$, and the cytotoxic effect rate constants are denoted by $k_{\text {death,pERK }}$ and $k_{\text {death,Total }} \mathrm{Rb}$. The effect of reduced mitosis on tumour growth, $E_{\mathrm{pHH} 3}$, is described below, where $\gamma$ is fixed to 0.241 (Tate et al., 2014):

$$
E_{\mathrm{pHH} 3}=\frac{\mathrm{pHH} 3^{\gamma}}{\mathrm{pHH} 3_{0}^{\gamma}}
$$

The apoptotic effect of pERK inhibition, $E_{\mathrm{pERK}}$, is given by:

$$
E_{\mathrm{pERK}}=\frac{\mathrm{pERK}_{0}-\mathrm{pERK}}{\mathrm{pERK}_{0}}
$$

As the resistance to vemurafenib therapy develops, the tumour becomes increasingly dependent on Total $\mathrm{Rb}$ expression for survival (Yadav et al., 2013). The apoptotic effect of Total $\mathrm{Rb}$ under resistant conditions was thus incorporated as the product of Total $\mathrm{Rb}$ and Cyclin D1 expression $\left(E_{\text {TotalRb }}\right)$. Therefore, when Cyclin D1 is overexpressed as a result of resistance to vemurafenib (Smalley et al., 2008; Yadav et al., 2014), administration of abemaciclib causes cell apoptosis and tumour shrinkage (Yadav et al., 2013). To prevent Total Rb-mediated tumour shrinkage occurring under non-resistant conditions, $E_{\text {TotalRb }}$ is set equal to zero if either Total $\mathrm{Rb}$ is above baseline or if Cyclin D1 is below baseline.

$$
\begin{aligned}
E_{\mathrm{TotalRb}}= & \frac{\text { TotalRb }_{0}-\text { TotalRb }_{\text {Trans } 2}}{\text { TotalRb }_{0}} \\
& \frac{\text { Cyclin D1 }-{\mathrm{Cyclin} \mathrm{D} 1_{0}}_{1}}{\text { Cyclin } \mathrm{D} 1_{0}}
\end{aligned}
$$

A schematic representation of the biomarker/tumour growth model is provided in Figure 1, showing the effect of vemurafenib under non-resistant conditions (A), and the acquisition of BRAF inhibitor resistance and efficacy mediated by abemaciclib under resistant conditions (B).

Model implementation and validation. The data were analysed in a sequential manner using NONMEM VII (ICON Development Solutions, Ellicott City, MD, USA). A population approach was used where longitudinal data were available. Model selection was based on goodness of fit and diagnostic plots, parameter estimate precision, the Akaike Information Criterion value and the Objective Function Value. Internal validation of the models was performed by graphical comparison of the raw data used to develop the model with the 5th, 50th and 95th percentiles of 1000 model simulations (visual predictive check (VPC)). In addition, external validation was performed by VPC of the model $v s$ experimental data not included in the fitting process, where available.

\section{RESULTS}

Biomarker response to abemaciclib in colo-205 and A375 xenograft tumour tissue. The cell cycle model previously developed for colo-205 xenograft tumours (Tate et al., 2014) was extended to include downregulation of Total $\mathrm{Rb}$ as a result of abemaciclib-mediated $\mathrm{pRb}$ inhibition (Shan et al., 1994). The refitted model successfully described the slow turnover rate of Total $\mathrm{Rb}$ and its modest inhibition after single and daily oral doses of $50 \mathrm{mg} \mathrm{kg}^{-1}$ abemaciclib (Supplementary Figure 1). The model parameters related to $\mathrm{pRb}$, TopoII $\alpha$ and $\mathrm{pHH} 3$ remain largely unchanged from the previous modelling effort (Tate et al., 2014), and as such, the model also successfully describes the concentration-dependent time course of $\mathrm{pRb}$, TopoII $\alpha$ and $\mathrm{pHH} 3$ (Table 1 and Supplementary Figure 1, additional data not shown).

The model was validated through accurate prediction of PK (data not shown) and biomarker response after 45 or $90 \mathrm{mg} \mathrm{kg}^{-1}$ of abemaciclib in A375 xenograft tumours by altering the initial conditions of the cell cycle biomarker model, and assuming 


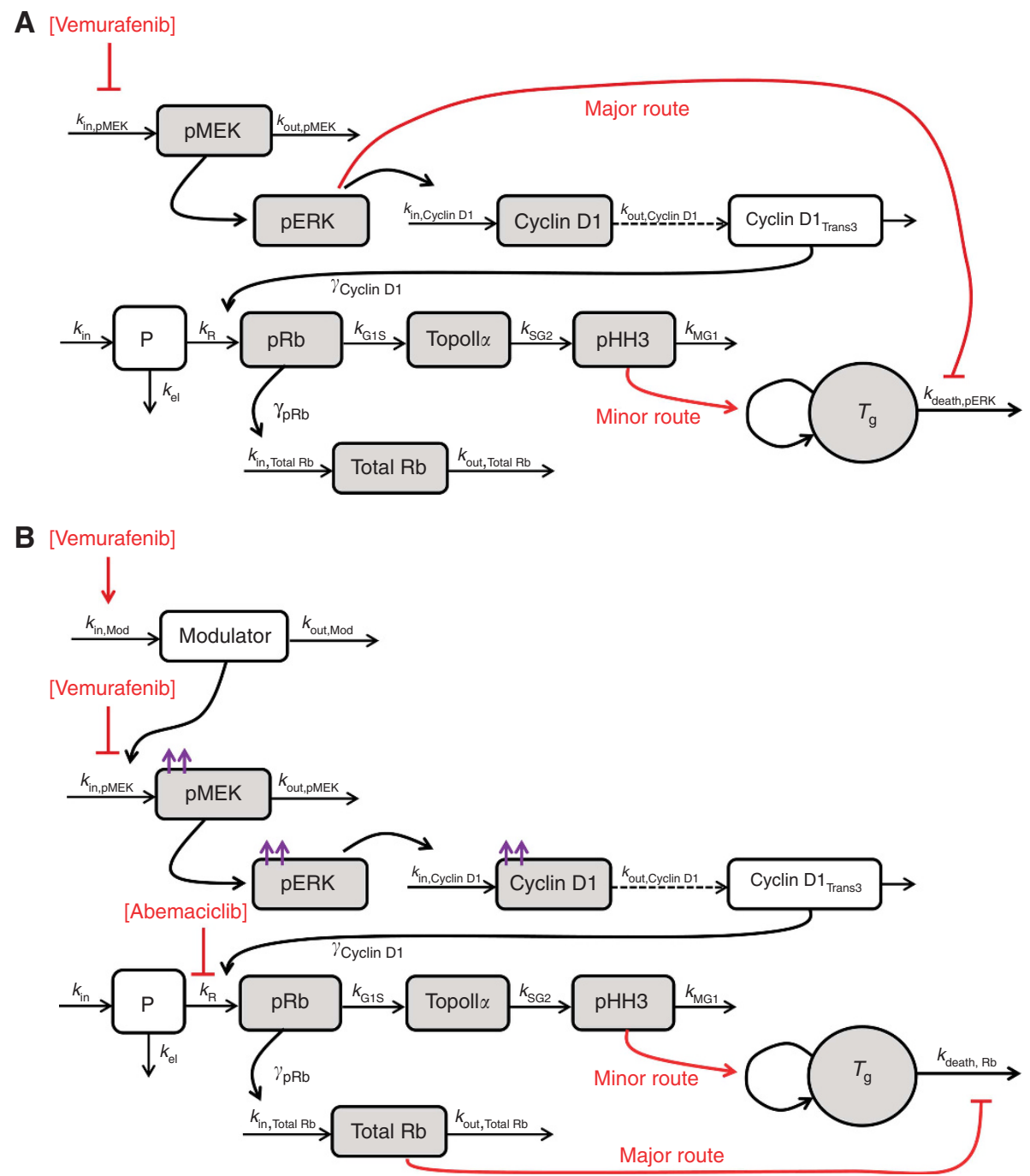

Figure 1. Schematic representation of the integrated semimechanistic PK/PD model describing (A) vemurafenib-meditated efficacy under nonresistant conditions through inhibition of the MAPK pathway and the cell cycle, and (B) acquisition of resistance to vemurafenib by the upregulation of the MAPK pathway and abemaciclib-mediated efficacy through cell cycle arrest and increased dependence on Total Rb for survival. Arrowheads denote positive relationships, flatheads denote negative relationships. Red arrows indicate route of efficacy; purple arrows indicate elevation of baseline biomarker levels as a result of vemurafenib resistance. Shaded boxes denote observed compartments. Parameters are defined in the text.

equivalent potency to colo-205 xenograft tumours (Supplementary Figure 2), as shown previously (Tate et al., 2014).

PK and biomarker response to vemurafenib in A375 xenograft tumour tissue. The disposition of orally administered vemurafenib in xenograft tumour-bearing mice was best described by a onecompartment PK model with saturable absorption, with a Michaelis constant $\left(K_{\mathrm{m}}\right)$ corresponding to a $19.9 \mathrm{mg} \mathrm{kg}^{-1}$ dose (Table 1, Supplementary Figure 3 and Supplementary Table 2). Notably, neither vemurafenib nor abemaciclib exhibited altered pharmacokinetics after coadministration (data not shown).

The PK model was then linked to a biomarker model describing the concentration-dependent effects of vemurafenib on pMEK and pERK (Dhillon et al., 2007, Yang et al., 2012), and the resulting inhibition of Cyclin D1 formation (Terada et al., 1999; Stacey, 2003) (Figure 2, Supplementary Figures 4-6). Inhibition of MEK phosphorylation by vemurafenib was potent and rapid, with an

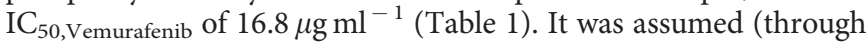
model testing) that vemurafenib was able to completely block pMEK synthesis (i.e. $I_{\max }=1$ ). Although pERK is downstream of
pMEK, the effect of vemurafenib-mediated inhibition of pMEK on pERK was found to be instantaneous. Cyclin D1 exhibits a much longer turnover half-life $(4 \mathrm{~h})$, resulting in maximum inhibition at $10 \mathrm{~h}$ after a $15 \mathrm{mg} \mathrm{kg}^{-1}$ dose of vemurafenib, compared with $2 \mathrm{~h}$ for upstream markers, pMEK and pERK (Figure 2).

By relating Cyclin D1 to the $\mathrm{pRb}$, the effect of vemurafenibmediated Cyclin D1 inhibition on cell cycle arrest (i.e. pRb, TopoII $\alpha$, pHH3 and Total Rb) (Stacey, 2003) was also captured (Table 1, Figure 2, Supplementary Figures 4-6). The model indicates that cell cycle progression is highly sensitive to Cyclin D1 expression; the same vemurafenib dose of $15 \mathrm{mg} \mathrm{kg}^{-1}$ inhibits Cyclin D1 by $33 \%$, which in turn inhibits pRb by $50 \%$ (Figure 2 ). Although initial inhibition of $\mathrm{pHH} 3$ appears modest (Figure 2), the model predicts that $15 \mathrm{mg} \mathrm{kg}^{-1}$ every $12 \mathrm{~h}$ inhibits $\mathrm{pHH} 3$ expression by $90 \%$ (under non-resistant conditions).

Inhibition of A375 xenograft tumour growth by vemurafenib acquisition of its resistance and subsequent efficacy by abemaciclib. The untreated growth of vehicle-treated A375 xenograft tumours was best described by the model previously 
Table 1. Parameter estimates for the integrated semimechanistic PK/PD model for vemurafenib and abemaciclib in mice bearing colo-205 or A375 xenograft tumours

\begin{tabular}{|c|c|c|c|}
\hline Parameter & $\begin{array}{c}\text { Colo-205 } \\
\text { xenograft } \\
\text { tumours }\end{array}$ & $\begin{array}{l}\text { A375 } \\
\text { xenograft } \\
\text { tumours } \\
\text { (model } \\
\text { estimation) }\end{array}$ & $\begin{array}{l}\text { A375 } \\
\text { xenograft } \\
\text { tumours } \\
\text { (external } \\
\text { validation) }\end{array}$ \\
\hline \multicolumn{4}{|c|}{ Biomarker model } \\
\hline $\begin{array}{l}I_{\max } \\
I_{50, \text { Abemaciclib }} \\
\left(\mathrm{ng} \mathrm{ml}^{-1}\right)\end{array}$ & $\begin{array}{l}0.907(1.7) \\
4.99(21)\end{array}$ & * & * \\
\hline $\begin{array}{l}\mathrm{IC}_{50, \text { Vemurafenib }} \\
\left(\mathrm{ng} \mathrm{ml}^{-1}\right)\end{array}$ & - & $16800(7.7)$ & ** \\
\hline$k_{\text {out,pMEK }}\left(h^{-1}\right)$ & - & $1.76(31)$ & ** \\
\hline$k_{\text {out }, \text { Cyclin D1 }}\left(h^{-1}\right)$ & - & $0.175(5.9)$ & ** \\
\hline $\begin{array}{l}\gamma_{\text {Cyclin D1 }} \\
k_{R}\left(\mathrm{~h}^{-1}\right)\end{array}$ & $0.154(6.3)$ & $\begin{array}{c}5 \text { (fixed) } \\
*\end{array}$ & $\begin{array}{c}* \star \\
*\end{array}$ \\
\hline$k_{\mathrm{G} 1 \mathrm{~S}}\left(\mathrm{~h}^{-1}\right)$ & $0.631^{a}$ & $0.618^{a}$ & ** \\
\hline$k_{\mathrm{SG} 2}\left(\mathrm{~h}^{-1}\right)$ & $0.0947^{a}$ & $0.445^{a}$ & ** \\
\hline$k_{\mathrm{MG} 1}\left(\mathrm{~h}^{-1}\right)$ & $0.272^{\mathrm{a}}$ & $1.98^{\mathrm{a}}$ & ** \\
\hline$k_{\mathrm{el}}\left(\mathrm{h}^{-1}\right)$ & $0.0463(29)$ & * & * \\
\hline$\gamma_{p R b}$ & $0.458(16)$ & * & * \\
\hline$k_{\text {out }, \text { Total Rb }}\left(\mathrm{h}^{-1}\right)$ & $0.0524(38)$ & * & * \\
\hline \multicolumn{4}{|l|}{ Tumour model } \\
\hline$\lambda_{0}\left(h^{-1}\right)$ & - & $0.00290(9.2)$ & $0.00350(5.4)$ \\
\hline$\lambda_{1}\left(\mathrm{mgh}^{-1}\right)$ & - & $5.16(41)$ & $6.31(14)$ \\
\hline$\omega_{0}(\mathrm{mg})$ & - & 26.6 (19) & $114(2.9)$ \\
\hline$k_{\text {death,pERK }}\left(h^{-1}\right)$ & - & $0.0128(29)$ & ** \\
\hline$k_{\text {out,modulator }}\left(\mathrm{h}^{-1}\right)$ & - & $0.00191(64)$ & ** \\
\hline Scalar & - & $0.0000616(26)$ & ** \\
\hline$k_{\text {death, } R b}\left(h^{-1}\right)$ & - & $0.00990(41)$ & ** \\
\hline \multicolumn{4}{|c|}{$\begin{array}{l}\text { For all fitted parameters, standard error of the estimate (\%) is given within parentheses. } \\
\text { Estimates of interindividual variability and residual error are provided in Supplementary } \\
\text { Table 3. - Not used in estimation or simulation. *Simulation performed using parameter } \\
\text { estimate obtained from colo- } 205 \text { xenograft tumour data. }{ }^{*} \text { Simulation performed using } \\
\text { parameter estimate obtained from A375 xenograft tumour data. } \\
{ }^{a} \text { Calculated from literature baseline values of cell density in the respective cell line. }\end{array}$} \\
\hline
\end{tabular}

developed by Simeoni et al (2004) (Figure 3A and Table 1). Vemurafenib-mediated tumour growth inhibition under nonresistant conditions was successfully captured by a model structure incorporating both the apoptotic effect of pERK inhibition (Mandal et al., 2014) and the cell growth inhibitory effect of pHH3 inhibition (Tate et al., 2014). This model indicates that $98 \%$ of antitumour activity is driven by pERK-related apoptosis, whereas the contribution of Cyclin D1-related cell cycle arrest is minimal (2\%).

Acquisition of resistance as a result of continuous vemurafenib treatment was best described by incorporating an upstream modulator compartment to induce overexpression of pMEK, pERK and Cyclin D1 (Das Thakur et al., 2013) (Figure 3A). Time to resistance was estimated to be $\sim 30$ days, whereupon pERK and Cyclin D1 levels are elevated nearly twofold over baseline. Moreover, sensitivity to abemaciclib monotherapy during vemurafenib resistance was successfully described by conditioning tumour cell survival to Total Rb when Cyclin D1 is overexpressed. The model indicates that under resistant conditions, $68 \%$ of abemaciclib-mediated tumour shrinkage is driven by sensitivity to Total $\mathrm{Rb}$, whereas the remaining $32 \%$ is attributed to cell cycle arrest.

Model validation: predicting tumour response in a second in vivo study. Model validation was performed by reestimating the growth of untreated A375 xenograft tumours in a second in vivo study and simulating the drug effect (Tate et al., 2014) elicited by vemurafenib and abemaciclib alone and in combination (Figure 3B and Table 1). As with the first in vivo study, untreated tumour growth was best described by the model previously developed by Simeoni et al (2004). The inhibitory effect of vemurafenib (10 $\mathrm{mg} \mathrm{kg}^{-1}$ twice a day) and abemaciclib ( $45 \mathrm{mg} \mathrm{kg}^{-1}$ every day) alone or in combination for 21 days was successfully predicted using the integrated semimechanistic tumour model. Owing to the short duration of the study, resistance to vemurafenib was neither present in the observed data nor in the model prediction.

Model predictions: identifying an optimum dosing schedule for the combination of abemaciclib and vemurafenib. Simulations of the model were performed to assess the optimum dosing schedule for vemurafenib and abemaciclib, providing insight into potentially efficacious clinical scenarios. Dosing regimens were constrained to those considered most clinically comparable $\left(15 \mathrm{mg} \mathrm{kg}^{-1}\right.$ twice a day for vemurafenib and $50 \mathrm{mg} \mathrm{kg}^{-1}$ every day for abemaciclib) (Grippo et al., 2014; Tate et al., 2014), whereas scheduling was varied across a range of monotherapy and combotherapy, and continuous and intermittent options. In accordance with experimental data (Das Thakur et al., 2013; Yadav et al., 2014), an intermittent schedule of vemurafenib ( $15 \mathrm{mg} \mathrm{kg}^{-1}$ twice a day for 2 weeks on a 3 -week cycle) was predicted to provide a more durable tumour response over continuous therapy $\left(15 \mathrm{mg} \mathrm{kg}^{-1}\right.$ twice a day) (Figure $4 \mathrm{C}$ vs Figure 4A). However, the onset of resistance was only delayed by intermittent vemurafenib therapy, eventually leading to tumour regrowth. The combination of continuous abemaciclib (50 $\mathrm{mg} \mathrm{kg}^{-1}$ every day) with continuous vemurafenib $\left(15 \mathrm{mg} \mathrm{kg}^{-1}\right.$ twice a day) was also predicted to provide superior benefit over continuous vemurafenib alone (Figure 4B vs Figure 4A), in accordance with previous observations (Yadav et al., 2014). However, the magnitude of response was comparable to that obtained with intermittent vemurafenib monotherapy, whereas resistance occurred more rapidly. Finally, continuous abemaciclib (50 $\mathrm{mg} \mathrm{kg}^{-1}$ every day) combined with intermittent vemurafenib (15 mg kg-1 twice a day for 2 weeks on a 3-week cycle) was predicted to maximise tumour response over either intermittent vemurafenib monotherapy or the combination of abemaciclib with continuous vemurafenib (Figure 4D). This optimised combination was predicted by the model to achieve complete tumour regression and prevent tumour regrowth throughout the duration of treatment.

\section{DISCUSSION}

In this study, an integrated semimechanistic PK/PD model was established describing efficacy and developing resistance to vemurafenib in A375 xenograft tumours, and heightened sensitivity to abemaciclib therapy arising as a result of continuous vemurafenib treatment. The purpose of developing such a model was (1) to characterise the quantitative pharmacology of abemaciclib-mediated efficacy in vemurafenib-resistant BRAFmutated melanoma, and (2) to identify an optimal dosing strategy for the abemaciclib/vemurafenib combination. To our knowledge, this is the first PK/PD modelling approach to mechanistically evaluate dose schedule optimisation for combination therapies in oncology.

A semimechanistic PK/PD model for abemaciclib in colo-205 xenograft tumours was previously shown to predict biomarker modulation ( $\mathrm{pRb}$, TopoII $\alpha$ and $\mathrm{pHH} 3$ ) and efficacy in A375 xenograft tumours (Tate et al., 2014). To describe abemaciclibmediated inhibition of Total $\mathrm{Rb}$, thought to be the mechanistic basis for sensitivity to CDK4/6 inhibition in vemurafenib-resistant tumours (Yadav et al., 2013), this PK/PD model was expanded in the current work to describe the downregulation of Total $\mathrm{Rb}$ as a result of $\mathrm{pRb}$ inhibition, caused by the inherent autoregulation of the E2F1-Rb pathway (Shan et al., 1994). To exploit the wealth of 

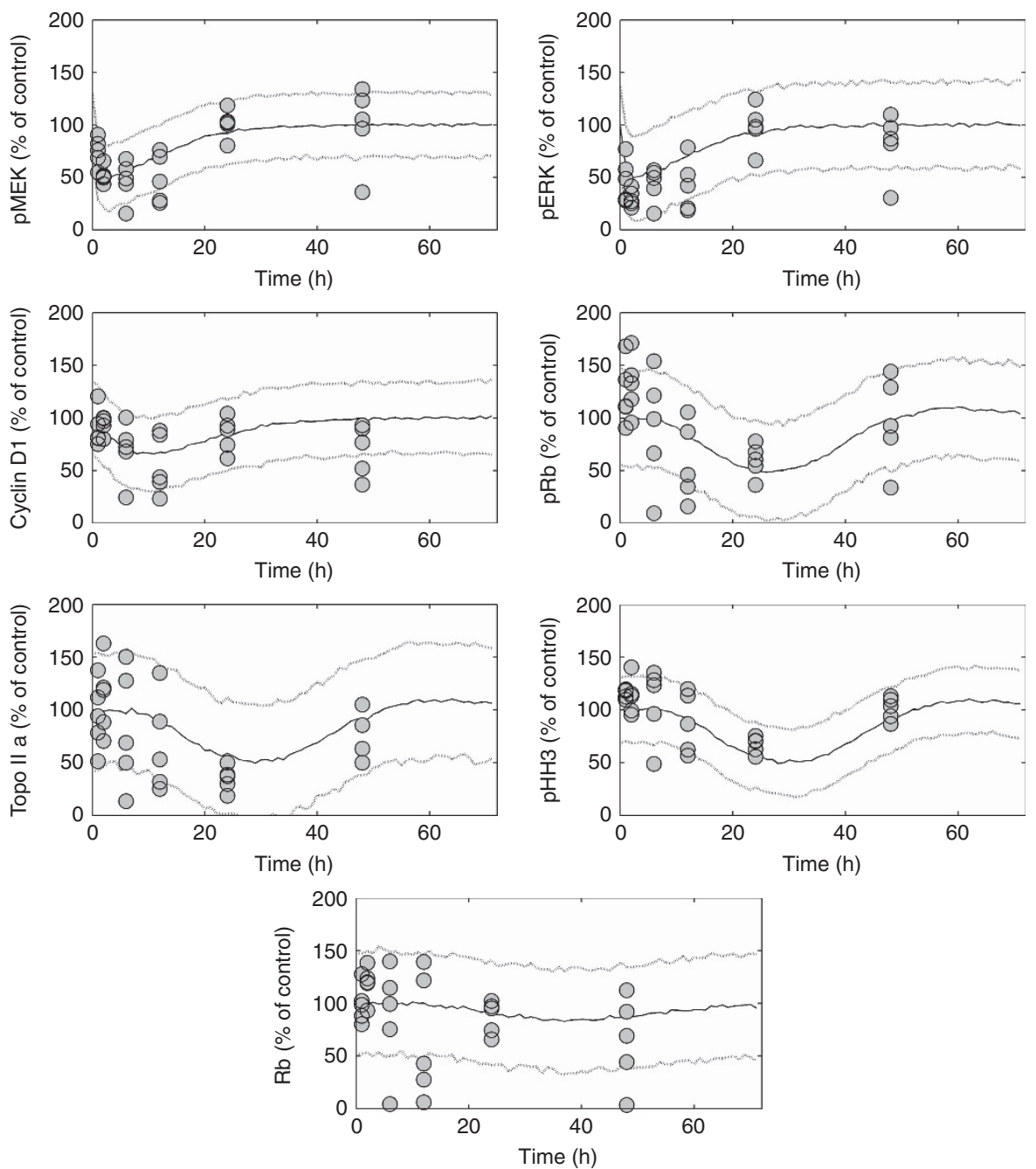

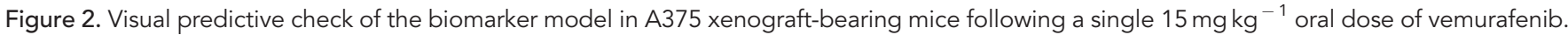
The circles denote observed pMEK, pERK, Cyclin D1, pRb, Topoll $\alpha, \mathrm{pHH} 3$ and Total Rb data in treated tumours, expressed as a percentage of the control value observed in the vehicle group. The solid and dotted lines represent the median, and the 5th and 95 th percentiles of 1000 individual model simulations, respectively.

in house biomarker data available in colo-205 xenograft tumours (Gelbert et al., 2014; Tate et al., 2014; Yadav et al., 2014), the dynamics of Total $\mathrm{Rb}$ inhibition were estimated using colo-205 data and, as before (Tate et al., 2014), the model was translated to A375 xenograft tumours by recalibration of the cell cycle. An updated, more intensively sampled data set provided a further and more robust validation analysis for biomarker response to abemaciclib in A375 xenograft tumours (Supplementary Figure 2).

Once the biomarker model for abemaciclib was successfully updated, the semimechanistic PK/PD model was further expanded to successfully describe vemurafenib-mediated inhibition of the MAPK pathway modulation (pMEK, pERK and Cyclin D1) and cell cycle arrest (pRb, TopoII $\alpha, \mathrm{pHH} 3$ and Total Rb). Tumour shrinkage was related to inhibition of $\mathrm{pERK}$ and $\mathrm{pHH} 3$, each describing efficacy as a result of apoptosis or cell cycle arrest, respectively (Lee et al., 2010). Model simulations reveal the majority of vemurafenib-mediated efficacy under non-resistant conditions is through pERK-related apoptosis (98\%), whereas cell cycle arrest has only a minimal effect on tumour growth inhibition. Internal-external validation of the model was achieved using a previously established technique (Tate et al., 2014), whereby uncontrolled tumour growth is refitted and the extent of tumour shrinkage as a result of drug treatment is accurately predicted (Figure 3B).
Although vemurafenib is initially efficacious, continuous treatment leads to resistance and tumour regrowth as a result of MAPK pathway reactivation (Trunzer et al., 2013). Resistance to vemurafenib was incorporated into the PK/PD model by use of a modulator compartment to mechanistically drive emerging upregulation of the MAPK pathway markers, pMEK, pERK and Cyclin D1. This modulator compartment can be considered an empirical approximation of the underlying genetic processes leading to resistance, which for A375 cells includes FGF-mediated ERK activation and/or p61-BRAF splicing (Yadav et al., 2014). As modulator upregulation is related to vemurafenib concentrations, resistance remains until cessation of vemurafenib treatment, at which point the biomarkers of the MAPK pathway gradually return to their original baseline levels and resistance is effectively reversed. This model structure is based on the growing evidence that vemurafenib resistance is reversible: altered EGFR expression levels as a result of vemurafenib treatment are counterselected in its absence (Sun et al., 2014), intermittent dosing delays tumour progression in preclinical models of BRAF-mutated melanoma (Das Thakur et al., 2013; Abdel-Wahab et al., 2014) and patients who have previously developed resistance to treatment have been successfully rechallenged with BRAF inhibition (Seghers et al., 2012; Romano et al., 2013). Most notably, resistance-related overexpression of pERK returns to near-normal levels during a 

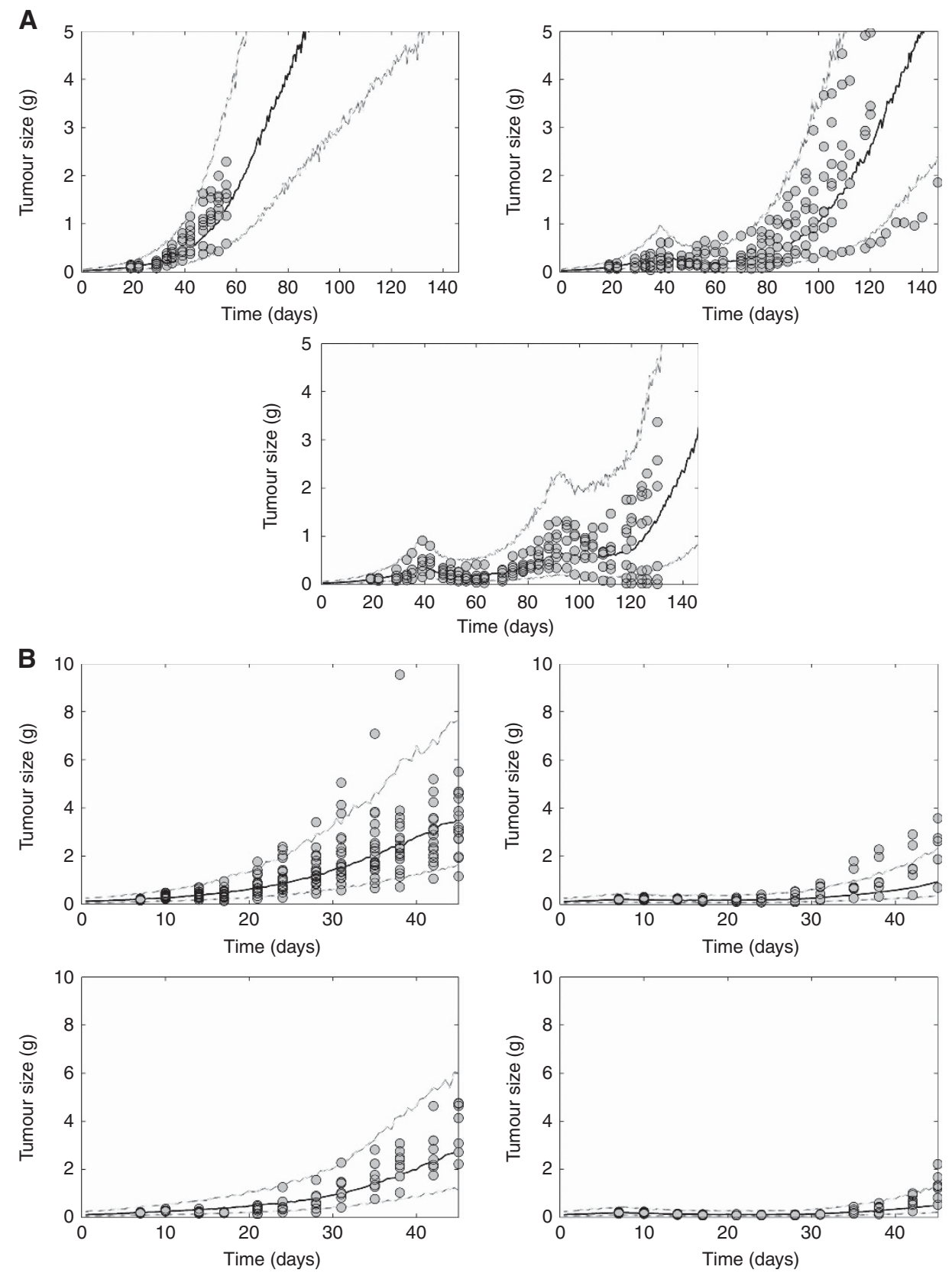

Figure 3. Visual predictive check of the tumour growth model in A375 xenograft-bearing mice for two studies: (A) after treatment with vehicle (top left) or with vemurafenib $15 \mathrm{mg} \mathrm{kg}^{-1}$ twice a day for 48 days, subsequently continuing with vemurafenib treatment (top right) or switching to $90 \mathrm{mg} \mathrm{kg}^{-1}$ abemaciclib every day for a further 28 days (bottom centre); and (B) after treatment with vehicle (top left) or with vemurafenib $10 \mathrm{mg} \mathrm{kg}^{-1}$ twice a day (top right) or abemaciclib $45 \mathrm{mg} \mathrm{kg}^{-1}$ every day alone (bottom left) or in combination for 21 days (bottom right). The circles denote observed A375 tumour size data. The solid and dotted lines represent the median, and the 5th and 95th percentiles of 1000 individual model simulations, respectively.

treatment holiday (Das Thakur et al., 2013), with a recovery rate that appears comparable to model estimates (half-life $\sim 6$ days). Consequently, by incorporating resistance to vemurafenib as a dynamic, reversible phenomenon, the PK/PD model was able to predict the additional benefit mediated by intermittent therapy over continuous treatment (Figure 4C). However, research in this area remains limited, and further work is required to investigate the apparent loss of resistance upon cessation of vemurafenib treatment and the clinical utility of an intermittent dosing schedule.

The CDK4/6 inhibitor, abemaciclib, was recently found to elicit a level of efficacy in vemurafenib-resistant A375 xenograft tumours, which was far greater than would be expected in treatment-naïve tumours (Yadav et al., 2014). This amplified sensitivity to abemaciclib is thought to be caused by an increased dependency on $\mathrm{Rb}$ expression for cell survival (Yadav et al., 2013). Resistant cells were also shown to be sensitive to Cyclin D1 expression, which is substantially elevated after continuous exposure to vemurafenib (Smalley et al., 2008; Yadav et al., 2014). As such, Cyclin D1 was incorporated as a marker of resistance in the PK/PD model, thus conditioning the model to increased sensitivity to inhibition of Total $\mathrm{Rb}$. Despite only moderate levels of inhibition ( $\sim 40 \%$ at $50 \mathrm{mg} \mathrm{kg}^{-1}$ every day), Total $\mathrm{Rb}$ is sufficiently reduced by abemaciclib to induce apoptosis in vemurafenib-resistant tumours. Indeed, while abemaciclib efficacy in non-resistant tumours is wholly attributed to cell cycle 

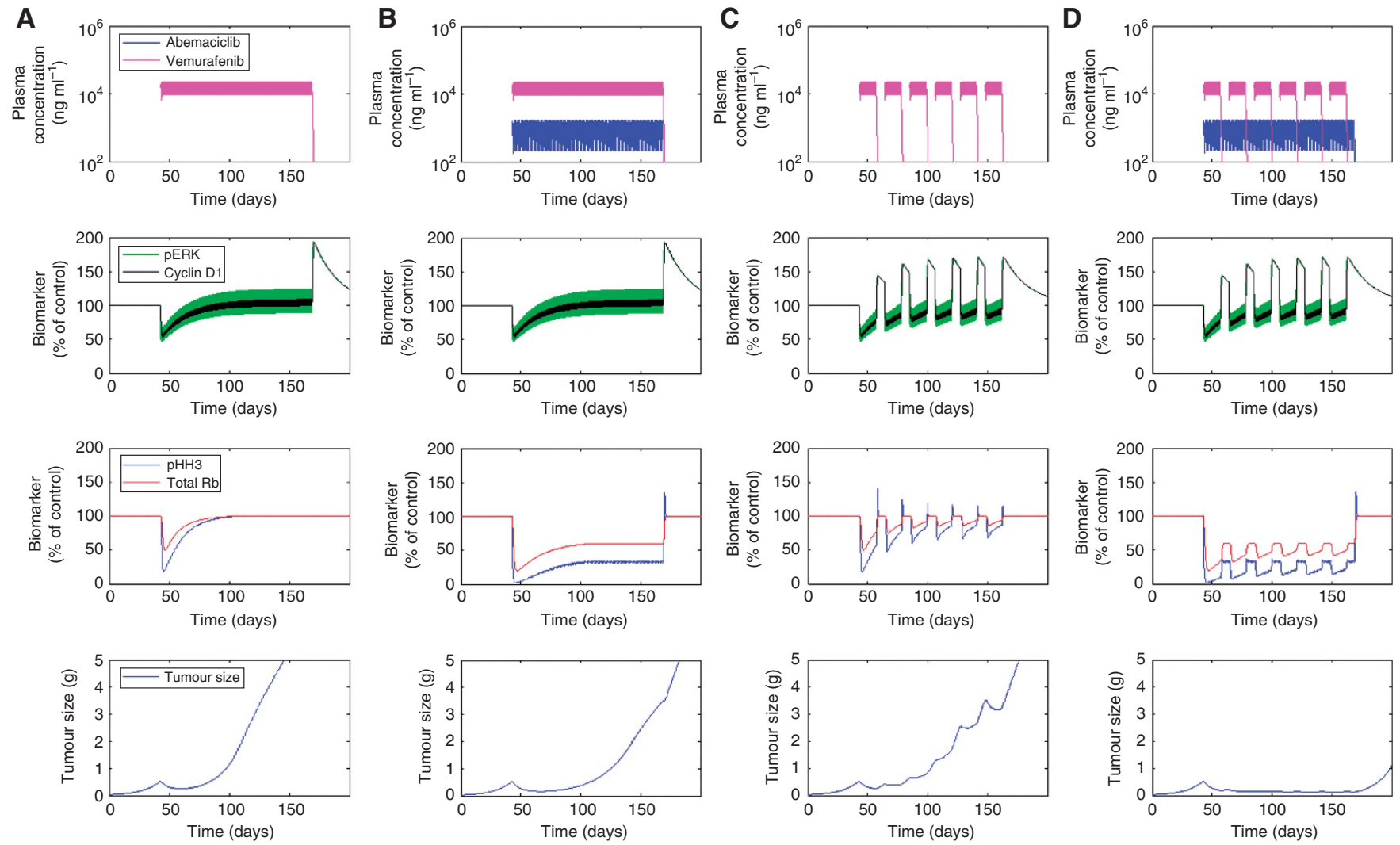

Figure 4. Simulations of the PK/biomarker/tumour growth model for four long-term dosing scenarios: (A) vemurafenib $15 \mathrm{mg} \mathrm{kg}^{-1} \mathrm{twice}$ a day given continuously, (B) vemurafenib $15 \mathrm{mg} \mathrm{kg}^{-1}$ twice a day and abemaciclib $50 \mathrm{mg} \mathrm{kg}^{-1}$ every day in combination, both given continuously, (C) vemurafenib $15 \mathrm{mg} \mathrm{kg}^{-1}$ twice a day given on an intermittent 2 weeks on/1 week off schedule, (D) intermittent vemurafenib $15 \mathrm{mg} \mathrm{kg}{ }^{-1}$ twice a day in combination with continuous abemaciclib $50 \mathrm{mg} \mathrm{kg}^{-1}$ every day.

arrest (50 $\mathrm{mg} \mathrm{kg}^{-1}$ every day) (Tate et al., 2014), the majority of tumour shrinkage in resistant tumours is mediated through sensitivity to Total $\mathrm{Rb}$ inhibition (68\%), rendering cell cycle arrest a minor route (32\%). Various dosing scenarios were explored using the PK/PD model; the strategy whereby vemurafenib is dosed intermittently during continuous abemaciclib treatment is predicted to be more effective than a continuous combination. This approach synergistically exploits both increased sensitivity to abemaciclib under vemurafenib-resistant conditions and improved sensitivity to BRAF inhibition after its temporary withdrawal. While the treatment schedule investigated in the current modelling work involves more frequent vemurafenib dosing (21-day cycle; 2 weeks on, 1 week off) than previous in vivo studies (42-day cycle; 4 weeks on, 2 weeks off; Das Thakur et al., 2013), the dosing intensity remains comparable $(2: 1)$. The higher frequency of treatment in the current study was designed to be amenable to common clinical practice; model simulations of the 42-day schedule are only marginally less effective than the 21-day cycle (data not shown). Furthermore, reducing the dosing intensity of vemurafenib (e.g. 1 week on, 2 weeks off) did not considerably worsen the predicted level of efficacy (data not shown), and may offer an opportunity to lessen the side effects associated with BRAF inhibition.

As the clinical doses for each inhibitor are well established, the $\mathrm{PK} / \mathrm{PD}$ model was designed to investigate optimum dosing schedules rather than to explore alternative dose levels. As such, the in vivo efficacy data for vemurafenib covered a limited dose range of $10-15 \mathrm{mg} \mathrm{kg}^{-1}$ twice a day. Although these doses exhibit exposure levels below clinical concentrations (Grippo et al., 2014), the sensitivity of A375 xenograft tumours to vemurafenib requires the use of lower doses (Wong et al., 2012). In contrast, the $50 \mathrm{mg} \mathrm{kg}^{-1}$ every day dose of abemaciclib in mouse achieves exposure levels that have been observed in patients demonstrating clinical efficacy (Tate et al., 2014). It is therefore considered that, within the constraints of xenograft sensitivity, the doses used in the current work are relevant to current clinical practice.

To conclude, previous xenograft studies have demonstrated the additional benefit of abemaciclib either in combination with vemurafenib in treatment-naïve human melanoma tumours or as a secondary monotherapy treatment in tumours that have already developed resistance to vemurafenib (Yadav et al., 2013; Yadav et al., 2014). In the current work, a PK/PD model developed to optimise the treatment schedules indicates that intermittent therapy with vemurafenib in combination with continuous abemaciclib treatment could lead to complete response in the median tumour volume (Figure 4D). This combination scenario allows resistance to wane during the break in vemurafenib dosing, whereas abemaciclib yields additional efficacy in resistant cells through inhibition of Total $\mathrm{Rb}$ (Figure 4D). Additional in vivo studies are required to fully assess the extent of tumour shrinkage mediated by intermittent vemurafenib and continuous abemaciclib, and to further validate the predictive ability of the combination PK/PD model.

\section{ACKNOWLEDGEMENTS}

We thank Dr Iñaki F Trocóniz for his insightful suggestions during the preparation of this manuscript. 


\section{CONFLICT OF INTEREST}

SCT is an employee of Eli Lilly and Company. TFB is an employee and shareholder of Eli Lilly and Company. DH is an employee of Eli Lilly and Company. PK is an employee and shareholder of Eli Lilly and Company. RPB is an employee and shareholder of Eli Lilly and Company. DMC is an employee and shareholder of Eli Lilly and Company.

\section{REFERENCES}

Abdel-Wahab O, Klimek VM, Gaskell AA, Viale A, Cheng D, Kim E, Rampal R, Bluth M, Harding JJ, Callahan MK, Merghoub T, Berger MF, Solit DB, Rosen N, Levine RL, Chapman PB (2014) Efficacy of intermittent combined RAF and MEK inhibition in a patient with concurrent BRAF- and NRAS-mutant malignancies. Cancer Discov 4 538-545.

Chapman PB, Hauschild A, Robert C, Haanen JB, Ascierto P, Larkin J, Dummer R, Garbe C, Testori A, Maio M, Hogg D, Lorigan P, Lebbe C, Jouary T, Schadendorf D, Ribas A, O'day SJ, Sosman JA, Kirkwood JM, Eggermont AM, Dreno B, Nolop K, Li J, Nelson B, Hou J, Lee RJ, Flaherty KT, Mcarthur GA (2011) Improved survival with vemurafenib in melanoma with BRAF V600E mutation. N Engl J Med 364: 2507-2516.

Das Thakur M, Salangsang F, Landman AS, Sellers WR, Pryer NK, Levesque MP, Dummer R, Mcmahon M, Stuart DD (2013) Modelling vemurafenib resistance in melanoma reveals a strategy to forestall drug resistance. Nature 494: 251-255.

DeCaprio JA, Ludlow JW, Lynch D, Furukawa Y, Griffin J, Piwnica-Worms H, Huang CM, Livingston DM (1989) The product of the retinoblastoma susceptibility gene has properties of a cell cycle regulatory element. Cell 58: 1085-1095.

Dhillon AS, Hagan S, Rath O, Kolch W (2007) MAP kinase signalling pathways in cancer. Oncogene 26: 3279-3290.

Dooley AJ, Gupta A, Bhattacharyya M, Middleton MR (2014) Intermittent dosing with vemurafenib in BRAF V600E-mutant melanoma: review of a case series. Ther Adv Med Oncol 6: 262-266.

Flaherty KT, Infante JR, Daud A, Gonzalez R, Kefford RF, Sosman J, Hamid O, Schuchter L, Cebon J, Ibrahim N, Kudchadkar R, Burris 3rd HA, Falchook G, Algazi A, Lewis K, Long GV, Puzanov I, Lebowitz P, Singh A, Little S, Sun P, Allred A, Ouellet D, Kim KB, Patel K, Weber J (2012) Combined BRAF and MEK inhibition in melanoma with BRAF V600 mutations. N Engl J Med 367: 1694-1703.

Gelbert LM, Cai S, Lin X, Sanchez-Martinez C, Del Prado M, Lallena MJ, Torres R, Ajamie RT, Kreklau E, Wishart GN, Flack RS, Neubauer B, Young J, Chan EM, Iversen P, Cronier D, De Dios A (2011) Identification and characterization of LY2835219: a potent oral inhibitor of the cyclin-dependent kinases 4 and 6 (CDK4/6) with broad in vivo antitumor activity. Mol Cancer Ther 10: B233.

Gelbert LM, Cai S, Lin X, Sanchez-Martinez C, Del Prado M, Lallena MJ, Torres R, Ajamie RT, Wishart GN, Flack RS, Neubauer BL, Young J, Chan EM, Iversen P, Cronier D, Kreklau E, De Dios A (2014) Preclinical characterization of the CDK4/6 inhibitor LY2835219: in vivo cell cycle-dependent/independent anti-tumor activities alone/in combination with gemcitabine. Invest New Drugs 32: 825-837.

Goswami PC, Roti Roti JL, Hunt CR (1996) The cell cycle-coupled expression of topoisomerase IIalpha during $\mathrm{S}$ phase is regulated by mRNA stability and is disrupted by heat shock or ionizing radiation. Mol Cell Biol 16: $1500-1508$.

Grippo JF, Zhang W, Heinzmann D, Yang KH, Wong J, Joe AK, Munster P, Sarapa N, Daud A (2014) A phase I, randomized, open-label study of the multiple-dose pharmacokinetics of vemurafenib in patients with BRAF V600E mutation-positive metastatic melanoma. Cancer Chemother Pharmacol 73: 103-111.

Gurley LR, Walters RA, Tobey RA (1974) Cell cycle-specific changes in histone phosphorylation associated with cell proliferation and chromosome condensation. J Cell Biol 60: 356-364.

Hauschild A, Grob JJ, Demidov LV, Jouary T, Gutzmer R, Millward M, Rutkowski P, Blank CU, Miller Jr WH, Kaempgen E, Martin-Algarra S, Karaszewska B, Mauch C, Chiarion-Sileni V, Martin AM, Swann S, Haney P, Mirakhur B, Guckert ME, Goodman V, Chapman PB (2012)
Dabrafenib in BRAF-mutated metastatic melanoma: a multicentre, open-label, phase 3 randomised controlled trial. Lancet 380: 358-365.

Huang WS, Wang JP, Wang T, Fang JY, Lan P, Ma JP (2007) ShRNAmediated gene silencing of beta-catenin inhibits growth of human colon cancer cells. World J Gastroenterol 13: 6581-6587.

Kitagawa M, Higashi H, Jung HK, Suzuki-Takahashi I, Ikeda M, Tamai K, Kato J, Segawa K, Yoshida E, Nishimura S, Taya Y (1996) The consensus motif for phosphorylation by cyclin D1-Cdk4 is different from that for phosphorylation by cyclin A/E-Cdk2. EMBO J 15: 7060-7069.

Koop A, Satzger I, Alter M, Kapp A, Hauschild A, Gutzmer R (2014) Intermittent BRAF-inhibitor therapy is a feasible option: report of a patient with metastatic melanoma. Br J Dermatol 170: 220-222.

Lam TL, Wong GK, Chow HY, Chong HC, Chow TL, Kwok SY, Cheng PN, Wheatley DN, Lo WH, Leung YC (2011) Recombinant human arginase inhibits the in vitro and in vivo proliferation of human melanoma by inducing cell cycle arrest and apoptosis. Pigment Cell Melanoma Res 24: 366-376.

Lee JT, Li L, Brafford PA, Van Den Eijnden M, Halloran MB, Sproesser K, Haass NK, Smalley KS, Tsai J, Bollag G, Herlyn M (2010) PLX4032, a potent inhibitor of the B-Raf V600E oncogene, selectively inhibits V600E-positive melanomas. Pigment Cell Melanoma Res 23: 820-827.

Mandal R, Raab M, Matthess Y, Becker S, Knecht R, Strebhardt K (2014) pERK 1/2 inhibit Caspase-8 induced apoptosis in cancer cells by phosphorylating it in a cell cycle specific manner. Mol Oncol 8: 232-249.

Romano E, Pradervand S, Paillusson A, Weber J, Harshman K, Muehlethaler K, Speiser D, Peters S, Rimoldi D, Michielin O (2013) Identification of multiple mechanisms of resistance to vemurafenib in a patient with BRAFV600E-mutated cutaneous melanoma successfully rechallenged after progression. Clin Cancer Res 19: 5749-5757.

Seghers AC, Wilgenhof S, Lebbe C, Neyns B (2012) Successful rechallenge in two patients with BRAF-V600-mutant melanoma who experienced previous progression during treatment with a selective BRAF inhibitor. Melanoma Res 22: 466-472.

Shan B, Chang CY, Jones D, Lee WH (1994) The transcription factor E2F-1 mediates the autoregulation of RB gene expression. Mol Cell Biol 14: 299-309.

Sheppard KE, McArthur GA (2013) The cell-cycle regulator CDK4: an emerging therapeutic target in melanoma. Clin Cancer Res 19: $5320-5328$.

Shi H, Hugo W, Kong X, Hong A, Koya RC, Moriceau G, Chodon T, Guo R, Johnson DB, Dahlman KB, Kelley MC, Kefford RF, Chmielowski B, Glaspy JA, Sosman JA, Van Baren N, Long GV, Ribas A, Lo RS (2014) Acquired resistance and clonal evolution in melanoma during BRAF inhibitor therapy. Cancer Discov 4: 80-93.

Simeoni M, Magni P, Cammia C, De Nicolao G, Croci V, Pesenti E, Germani M, Poggesi I, Rocchetti M (2004) Predictive pharmacokineticpharmacodynamic modeling of tumor growth kinetics in xenograft models after administration of anticancer agents. Cancer Res 64: 1094-1101.

Smalley KS, Lioni M, Dalla Palma M, Xiao M, Desai B, Egyhazi S, Hansson J, Wu H, King AJ, Van Belle P, Elder DE, Flaherty KT, Herlyn M, Nathanson KL (2008) Increased cyclin D1 expression can mediate BRAF inhibitor resistance in BRAF V600E-mutated melanomas. Mol Cancer Ther 7: 2876-2883.

Stacey DW (2003) Cyclin D1 serves as a cell cycle regulatory switch in actively proliferating cells. Curr Opin Cell Biol 15: 158-163.

Sun C, Wang L, Huang S, Heynen GJ, Prahallad A, Robert C, Haanen J, Blank C, Wesseling J, Willems SM, Zecchin D, Hobor S, Bajpe PK, Lieftink C, Mateus C, Vagner S, Grernrum W, Hofland I, Schlicker A, Wessels LF, Beijersbergen RL, Bardelli A, Di Nicolantonio F, Eggermont AM, Bernards R (2014) Reversible and adaptive resistance to BRAF(V600E) inhibition in melanoma. Nature 508: 118-122.

Tap WD, Gong KW, Dering J, Tseng Y, Ginther C, Pauletti G, Glaspy JA, Essner R, Bollag G, Hirth P, Zhang C, Slamon DJ (2010) Pharmacodynamic characterization of the efficacy signals due to selective BRAF inhibition with PLX4032 in malignant melanoma. Neoplasia 12: 637-649.

Tate SC, Cai S, Ajamie RT, Burke T, Beckmann RP, Chan EM, De Dios A, Wishart GN, Gelbert LM, Cronier DM (2014) Semi-mechanistic pharmacokinetic/pharmacodynamic modeling of the antitumor activity of LY2835219, a new cyclin-dependent kinase 4/6 inhibitor, in mice bearing human tumor xenografts. Clin Cancer Res 20: 3763-3774. 
Terada Y, Inoshita S, Nakashima O, Kuwahara M, Sasaki S, Marumo F (1999) Regulation of cyclin D1 expression and cell cycle progression by mitogen-activated protein kinase cascade. Kidney Int 56: 1258-1261.

Trunzer K, Pavlick AC, Schuchter L, Gonzalez R, Mcarthur GA, Hutson TE, Moschos SJ, Flaherty KT, Kim KB, Weber JS, Hersey P, Long GV, Lawrence D, Ott PA, Amaravadi RK, Lewis KD, Puzanov I, Lo RS, Koehler A, Kockx M, Spleiss O, Schell-Steven A, Gilbert HN, Cockey L, Bollag G, Lee RJ, Joe AK, Sosman JA, Ribas A (2013) Pharmacodynamic effects and mechanisms of resistance to vemurafenib in patients with metastatic melanoma. J Clin Oncol 31: 1767-1774.

Wong H, Vernillet L, Peterson A, Ware JA, Lee L, Martini JF, Yu P, Li C, Del Rosario G, Choo EF, Hoeflich KP, Shi Y, Aftab BT, Aoyama R, Lam ST, Belvin M, Prescott J (2012) Bridging the gap between preclinical and clinical studies using pharmacokinetic-pharmacodynamic modeling: an analysis of GDC-0973, a MEK inhibitor. Clin Cancer Res 18: 3090-3099.

Yadav V, Burke TF, Huber L, Van Hoen RD, Zhang Y, Buchanan S, Chan EM, Starling JJ, Beckmann RP, Peng S-B (2013) The CDK4/6 inhibitor LY2835219 overcomes vemurafenib resistance resulting from MAPK reactivation and cyclin D1 upregulation. Mol Cancer Ther 12: C88.
Yadav V, Burke TF, Huber L, Van Horn RD, Zhang Y, Buchanan SG, Chan EM, Starling JJ, Beckmann RP, Peng SB (2014) The CDK4/6 inhibitor LY2835219 overcomes vemurafenib resistance resulting from MAPK reactivation and cyclin D1 upregulation. Mol Cancer Ther 13: 2253-2263.

Yadav V, Chen SH, Yue YG, Buchanan S, Beckmann RP, Peng SB (2015) Co-targeting BRAF and cyclin dependent kinases $4 / 6$ for BRAF mutant cancers. Pharmacol Ther 149: 139-149.

Yang H, Higgins B, Kolinsky K, Packman K, Bradley WD, Lee RJ, Schostack K, Simcox ME, Kopetz S, Heimbrook D, Lestini B, Bollag G, Su F (2012) Antitumor activity of BRAF inhibitor vemurafenib in preclinical models of BRAF-mutant colorectal cancer. Cancer Res 72: 779-789.

(c) (i)(2) This work is licensed under the Creative Commons BY ${ }_{\text {NC }}$ SA Attribution-Non-Commercial-Share Alike 4.0 International License. To view a copy of this license, visit http:// creativecommons.org/licenses/by-nc-sa/4.0/

Supplementary Information accompanies this paper on British Journal of Cancer website (http://www.nature.com/bjc) 